\title{
Influence of Tube and Particle Diameter on Heat Transport in Packed Beds
}

\author{
J. G. H. Borkink and K. R. Westerterp \\ Chemical Reaction Engineering Laboratories, Dept. of Chemical Engineering, Twente University of Technology, \\ 7500 AE Enschede, The Netherlands
}

\begin{abstract}
Influence of the tube and particle diameter and shape, as well as their ratio, on the radial heat transport in packed beds has been studied. Heat transport experiments were performed with four different packings in three wall-cooled tubes, which differed in inner diameter only. Experimental values for the effective radial heat conductivity and wall heat-transfer coefficient for the pseudo-homogeneous twodimensional model and the overall heat-transfer coefficient for the one-dimensional model are presented. Values were obtained for glass spheres, alumina cylinders, and alumina Raschig rings. The effective radial heat conductivity and wall heat-transfer coefficient can both be correlated as a linear function of the gas flow rate. The Bodenstein number for heat at fully developed turbulent flow is influenced strongly by the shape of the packing: 10.9 for glass spheres, 7.6 for alumina cylinders, and 4.2 for alumina Raschig rings. For the same packing, no significant influence is found of the tube diameter on the effective radial heat conductivity or on the wall heat-transfer coefficient. The overall heat-transfer coefficient can be described very well by the so-called "lump equation," which gives the relations among the overall heat-transfer coefficient, effective radial heat conductivity, and wall heat-transfer coefficient. The "lump factor," as used in the lump equation, has a best-fit experimental value of 7.4 .
\end{abstract}

\section{Introduction}

A wall-cooled tubular reactor, with a low tube-to-particle diameter ratio, is often used to perform highly exothermic catalytic reactions in industry. A major problem with such a reactor is the possibility of a temperature runaway to high temperatures. To prevent this, it is important to study the behavior of the reactor a priori by computer simulation. For such a simulation, a good mathematical reactor model is needed, capable of accurately predicting the temperature and concentration profiles, given a certain reactor design (such as tube diameter and length, and particle diameter and shape) and operating conditions (such as gas flow rate, inlet temperature and concentrations, and coolant temperature). When deriving a reactor model, usually the reaction kinetics and heatand mass-transport phenomena are separated and described by effective kinetic and heat- and mass-transport coefficients. These coefficients are preferably obtained from experiments,

Correspondence concerning this article should be addressed to $K$. R. Westerterp. which are performed on a much smaller scale than the actual industrial reactor.

This article is concerned with obtaining effective heat-transport coefficients from experiments without a chemical reaction. Especially, the influence of the tube and the particle diameter and their ratio, as well as that of the particle shape, is studied. Modeling catalytic fixed-bed reactors are discussed by researchers including: Singh et al. (1974), Hofmann (1979), Westerterp et al. (1984), Eigenberger and Ruppel (1985), Froment and Hofmann (1986), Khanna and Seinfeld (1987), Odendaal et al. (1987), Windes et al. (1989a, b), Schwedock et al., (1989), Feyo de Azevedo et al. (1990), Froment and Bischoff (1990), and Westerink et al. (1990).

\section{Types of models}

Heat transport in wall-cooled packed beds can be described by different types of models. First, there are deterministic- 
and stochastic-type models. With the latter, the results are different every time the calculation is done for the same conditions, depending on some random nature of one or more of the coefficients used in the model. Most models presented in literature are deterministic, although several use stochastic modeling, especially for studying residence time distributions using Markov-chain modeling and Monte-Carlo simulation (Krambeck et al., 1967; Schmalzer and Hoelscher, 1971; Berryman and Himmelblau, 1973; Kado and Himmelblau, 1973; Raghuraman and Mohan, 1975). Second, there are discrete models, which use difference equations, and continuum models, which use differential equations. Until the early 70 s, discrete modeling was often used, especially for modeling threephase systems, like trickle-flow columns (Deans and Lapidus, 1960a, b; Olbrich et al., 1966; Jameson, 1966; Porter, 1968; Rhee et al., 1973). But, since the large-scale introduction of the computer, continuum modeling became more popular. Although several investigators recently have switched to discrete modeling (for example, Klingman and Lee, 1987; Schnitzlein and Hofmann, 1987). We will focus on deterministic continuum models.

When using a continuum model, one can distinguish between a heterogeneous (or two-phase) and a pseudo-homogeneous (or one-phase) model. The latter is often used for modeling steady-state heat transfer in a wall-cooled or wall-heated packed bed, because temperature differences between the solid and the gas phase are expected to be small. Also, one-dimensional and two-dimensional models can be distinguished, depending on whether the radial temperature profile is taken into account or averaged to a so-called "mean-cup" temperature. Furthermore, it is possible to take axial dispersion of heat into account or neglect it.

For a more general discussion of the description of heat and mass transport in packed beds with deterministic continuum models and available correlations for the transport coefficients, see, for example, Bauer (1977), Kulkarni and Doraiswamy (1980), Wakao and Kaguei (1982), Ziolkowski and Legawiec (1987), Dixon (1988), and Schlünder and Tsotsas (1988).

\section{Developments in literature}

In this article, pseudo-homogeneous one- and two-dimensional models are used to describe heat transport in packed beds with a low tube-to-particle diameter ratio. Major developments for these type of models and for the parameters used are briefly discussed.

Colburn (1931) was one of the early pioneers, who used a pseudo-homogeneous one-dimensional model to describe the heat transport in a wall-heated packed bed with a low tubeto-particle diameter ratio. His work was later extended by Leva (1947) and Leva and Grummer (1948). A heterogeneous twodimensional model with axial dispersion of heat was presented by Hall and Smith (1949). But, they evaluated their results using a pseudo-homogeneous model with an effective overall heat conductivity in radial and axial direction. They noticed a sharp decrease of this thermal conductivity near the tube wall, which was also observed by Bunnell et al. (1949). It was suggested (Morales et al., 1951) that this decrease in effective radial heat conductivity was the result of a nonuniform radial velocity profile. Coberly and Marshall (1951) also used a pseudo-homogeneous two-dimensional model to interpret their measurements, but they introduced a wall heat-transfer coefficient, accounting for the decrease in heat conductivity near the tube wall.

Until about 1955, most correlations for the effective heattransport coefficients were obtained empirically. Calderbank and Progorski (1957) and Yagi and Kunii (1957) were among the first to relate the effective radial heat conductivity, which is a lumped parameter, to the underlying heat-transport phenomena. The following mechanisms, independent of fluid flow, were recognized (see also Argo and Smith, 1953):

1. Thermal conduction through the stagnant fluid

2. Thermal conduction through the solid

3. Thermal conduction through the contact surfaces of two particles

4. Radiant heat transfer between surfaces of particles

5. Radiant heat transfer between neighboring voids.

The following mechanisms, dependent of fluid flow, were also recognized:

6. Thermal conduction through the fluid film near the contact surface of two particles

7. Heat transfer by convection solid-fluid-solid

8. Heat transfer by lateral mixing of fluid due to the dividing and mixing of fluid filaments passing round particles of packing.

It was assumed by Yagi and Kunii (1957) that mechanisms 3 and 6 act in parallel and that these act is series with mechanism 2. Mechanisms 1, 2, 4, 5, 7 and 8 were supposed to act in parallel. They assumed the contribution of mechanism 7 to be neglectable compared to the others and that the flow dependence of mechanism 6 is small. Their work was extended later by themselves and several others, like Kunii and Smith (1960), Wakao and Kato (1969), and Zehner and Schlünder (1970, 1973). A similar approach was used by Yagi and Kunii (1960) to develop a theoretically based equation for the wall heattransfer coefficient (see also Yagi and Wakao, 1959).

For mechanism 8 it was found that at fully developed turbulent flow, the radial Bodenstein number should have a value of about 11, independent of the Reynolds number (Bernard and Wilhelm, 1950; Baron, 1952). Schlünder (1966) theoretically derived a value of 8 , by assuming that the radial dispersion distance equals the particle diameter. Near the wall, a value of 16 was obtained, by assuming total reflection of the gas, and an interpolation formula was presented. Later, Tsotsas and Schlünder (1988) showed that it is not the reflection at the wall that increases the Bodenstein number, but the lower superficial gas velocity in the center of the packed bed, due to the phenomenon of wall-channelling of the gas. This is similar to the results of Fahien and Smith (1955), who found an increase of the radial Bodenstein number with the radius.

Crider and Foss (1965) theoretically derived the relation between the overall heat-transfer coefficient of the one-dimensional model and the effective radial heat conductivity and wall heat-transfer coefficient of the two-dimensional model. This relation is referred to as the "lump equation," containing the so-called "lump factor," see Eq. 17. They argued that the value of 8 for this factor, as was found by Beek (1962), is valid only for low values of the wall Biot number and suggested a value of 6.13. Later, Froment (1967) again derived a value of 
8, which was also found by Finlayson (1971), for the case of no reaction.

Analytical expressions for the heat-transport coefficients of the pseudo-homogeneous models were presented by Dixon and Cresswell $(1979,1986)$ and Dixon $(1985 a)$. These were derived from the heterogeneous two-dimensional model, for which they assumed that it "describes the essential underlying and independently measurable heat-transport processes." These heat-transport processes were studied individually in a series of articles (Dixon et al., 1984; Melanson and Dixon, 1985; Dixon and Labua, 1985; Dixon, 1988). The approach used by them is similar to the one used by Vortmeyer and Schaefer (1974) and Vortmeyer (1989), who relate the axial dispersion coefficient, as used in the pseudo-homogeneous model for an adiabatic packed bed, to the parameters of the heterogeneous model.

Besides, the investigations mentioned above, several other authors have measured and correlated the effective radial heat conductivity, the wall heat-transfer coefficient, and the overall heat-transfer coefficient for wall-cooled or wall-heated packed beds (see, for example, Plautz and Johnstone, 1955; Kunii et al., 1968; Schertz and Bischoff, 1969; Agnew and Potter, 1970; De Wasch and Froment, 1972; Olbrich and Potter, 1972; Gunn and Khalid, 1975; Wellauer et al., 1982; Borman et al., 1992).

Since 1975, few studies have been presented giving experimentally determined values for the effective heat-transport coefficients. Instead, several authors tried to explain the large spread found for these coefficients by a critical re-evaluation of the data presented in literature. This was done by incorporating phenomena into the models, that were not considered in the original articles, like the inclusion of axial dispersion of heat, a radial velocity profile, a radially varying effective heat conductivity, and a nonflat radial inlet temperature profile (see, for example, Hennecke and Schlünder, 1973; Li and Finlayson, 1977; Dixon, 1985b; Ziolkowski and Legawiec, 1987; Gunn et al., 1987).

Lately, there is a tendency in literature to use more elaborate models when modeling gas-solid packed bed reactors. There is a shift from the steady-state, pseudo-homogeneous, oneand two-dimensional models toward the dynamic, heterogeneous two-dimensional model (see Khanna and Seinfeld, 1987; Odendaal et al., 1987; Gatica et al., 1989; Windes et al., 1989a, b).

As can be seen from the preceding, much research has been concerned with describing heat transport in packed tubes, especially for low tube-to-particle diameter ratios. This is of particular interest, because at a small number of particles on a diameter the uncertainty is largest as to which parameter values should be used for the modeling of packed-bed reactors, due to the large spread found in literature values for the heattransport coefficients. The influence of the tube-to-particle diameter ratio is usually studied by changing the particle size at the same tube diameter. It would be interesting though to study the influence of changing the tube diameter at the same particle size and of changing the tube diameter and the particle size simultaneously at a constant tube-to-particle diameter ratio, as was pointed out already by Dixon (1988). In this article, this is done by determining values for the effective radial heat conductivity $\lambda_{e, r}$, the wall heat-transfer coefficient $\alpha_{w}$ and the overall heat-transfer coefficient $U_{o v}$ in three different wallcooled tubes and with four different packings.

\section{Model Equations and Experimental Setup Model equations}

The system studied is a hot gas, cooled down in a wallcooled packed bed with a small number of particles on a diameter. For modeling the heat transport in the experimental equipment used, we made the following assumptions:

- The system is in steady state and no reaction takes place.

- The system is considered to be pseudo-homogeneous.

- There is no axial dispersion of heat.

- There is no free convection of heat.

- There is no radiation.

- The superficial velocity is constant over the radius.

- The pressure is constant in the packed bed.

- The wall temperature is constant.

- The physical properties of the gas and the solid are independent of temperature.

- The inlet temperature profile can be described by a parabola.

A heat balance for an infinitesimally small ring yields the following pseudo-homogeneous two-dimensional model:

$$
\frac{\partial \theta}{\partial \omega}=\frac{1}{B o_{h, \rho}^{\theta} \rho} \frac{\partial}{\partial \rho}\left[\rho \frac{\partial \theta}{\partial \rho}\right]
$$

subject to

$$
\begin{array}{ll}
\omega=0, \text { all } \rho, & \theta=1-A \rho^{2} \\
\rho=0, \text { all } \omega, & 0 \leq \theta \leq 1 \\
\rho=1, \text { all } \omega, & \frac{\partial \theta}{\partial \rho}=-B i_{t} \theta
\end{array}
$$

In these equations, $\theta$ is given by $\theta=\left(T_{z, r}-T_{c l}\right) /\left(T_{0}-T_{c l}\right)$, where $T_{0}$ is the temperature measured in the center of the packed bed after a certain minimum bed length, taken as the place where $\omega=0$. Values for the constant $A$ are obtained by fitting Eq. 2a to the experimentally determined radial temperature profile at this position. The minimum bed length is chosen such that constant $A$ does not significantly change with bed length any more. This proved to be the case for a minimum bed length of about 10-20 particle diameters. It can be shown that the values obtained for constant $A$ are close to those theoretically obtained by substitution of Eq. 2a into Eq. 2c, yielding: $A=B i_{t} /\left(2+B i_{t}\right)$ (Borkink et al., 1992a). Equation 1 together with Eqs. $2 a-2 c$ can be solved to yield:

$$
\begin{aligned}
& \theta(\rho, \omega) \\
& =2 \sum_{i=1}^{\infty}\left\{\frac{\left[\left(B i_{t} \beta_{i}^{2}+4 A B i_{t}-2 A \beta_{i}^{2}-A B i_{t} \beta_{i}^{2}\right) J_{0}\left(\beta_{i} \rho\right)\right]}{\beta_{i}^{3}\left[\beta_{i} J_{0}\left(\beta_{i}\right)+B i_{t} J_{1}\left(\beta_{i}\right)\right]} \exp \left[\frac{-\beta_{i}^{2} \omega}{B o_{h, r}^{\theta}}\right]\right\}
\end{aligned}
$$

in which $\beta_{i}$ is found from

$$
\beta_{i} J_{1}\left(\beta_{i}\right)-B i_{t} J_{0}\left(\beta_{i}\right)=0
$$

Equation 3 describes the axial and radial temperature profile with two model parameters $B o_{h, r}^{\ominus}$ and $B i_{l}$, containing the ef- 
fective radial heat conductivity $\lambda_{e, r}$ and the wall heat-transfer coefficient $\alpha_{w}$.

A heat balance for an infinitesimally small disc, assuming constant radial temperature, yields the following pseudo-homogeneous one-dimensional model:

$$
\frac{\partial \theta^{M C}}{\partial \omega}=-4 S t^{\theta} \theta^{M C}
$$

with the inlet condition:

$$
\omega=0, \quad \theta^{M C}=\theta_{0}^{M C}
$$

Solving Eq. 5 together with Eq. 6 yields:

$$
\theta^{M C}=\theta_{0}^{M C} \exp \left(-4 S t^{\ominus} \omega\right)
$$

In these equations $\theta^{M C}$ is the so-called "mean-cup temperature," calculated according to:

$$
\theta^{M C}=2 \int_{0}^{1} \rho \theta(\rho, \omega) d \rho
$$

It should be noted that Eq. 8 is valid only for a radially flat superficial velocity profile. Equation 5 describes the axial temperature profile with only one model parameter $S t^{\Theta}$, containing the overall heat-transfer coefficient $U_{o v}$.
Values for $U_{o v}, \lambda_{e, r}$ and $\alpha_{w}$ for the two models were obtained by fitting Eqs. 3 and 7 to experimentally determined temperature profiles. The objective function minimized was a chisquare target function, calculated according to:

$$
\chi^{2}=\sum_{i=1}^{n}\left(\frac{\theta_{i}-\theta\left(\rho, \omega, U_{o v}, \lambda_{e, r}, \alpha_{w}\right)}{\sigma_{i}}\right)^{2}
$$

In this equation, $n$ is the number of measured temperatures, $\theta_{i}$ is the experimentally obtained temperature, $\theta\left(\rho, \omega, U_{o v}, \lambda_{e, r}\right.$, $\left.\alpha_{w}\right)$ is the value predicted by the models, and $\sigma_{i}$ is the standard deviation for the measured temperatures. The chi-square target function was minimized using a Nealder-Mead method in multidimensions with different starting points (Press et al., 1989).

\section{Experimental Setup}

The setup to measure radial and axial temperature profiles contained three stainless steel wall-cooled tubes, with a length of $1.33 \mathrm{~m}$ and inner diameters of $49.9,63.5$ and $99.0 \mathrm{~mm}$, respectively. The tubes were filled with a packing and cooled at the wall with water of about $283 \mathrm{~K}$, flowing through a jacket. Hot air with a temperature of about $333 \mathrm{~K}$ flowed upward through the tubes and was cooled down at the wall. In the steady state, the radial temperature profile was measured in the packed bed near the top with 7 to $15 \mathrm{~K}$-type thermocouples of $0.5 \mathrm{~mm}$ in diameter, fixed in a rectangular rod of $2 \times 2 \mathrm{~mm}$, which was placed radially through the center of the packed

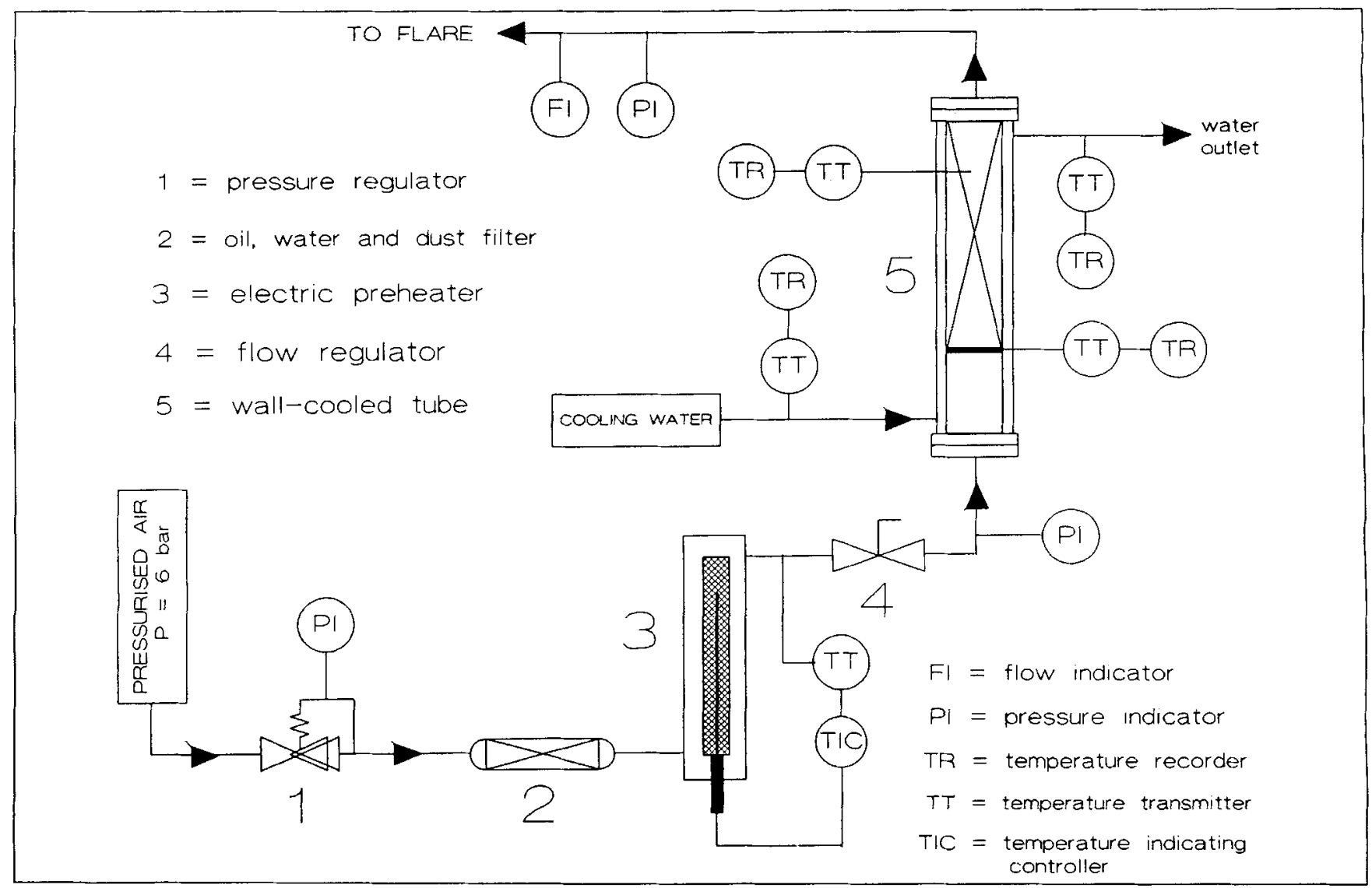

Figure 1. Experimental sefup. 


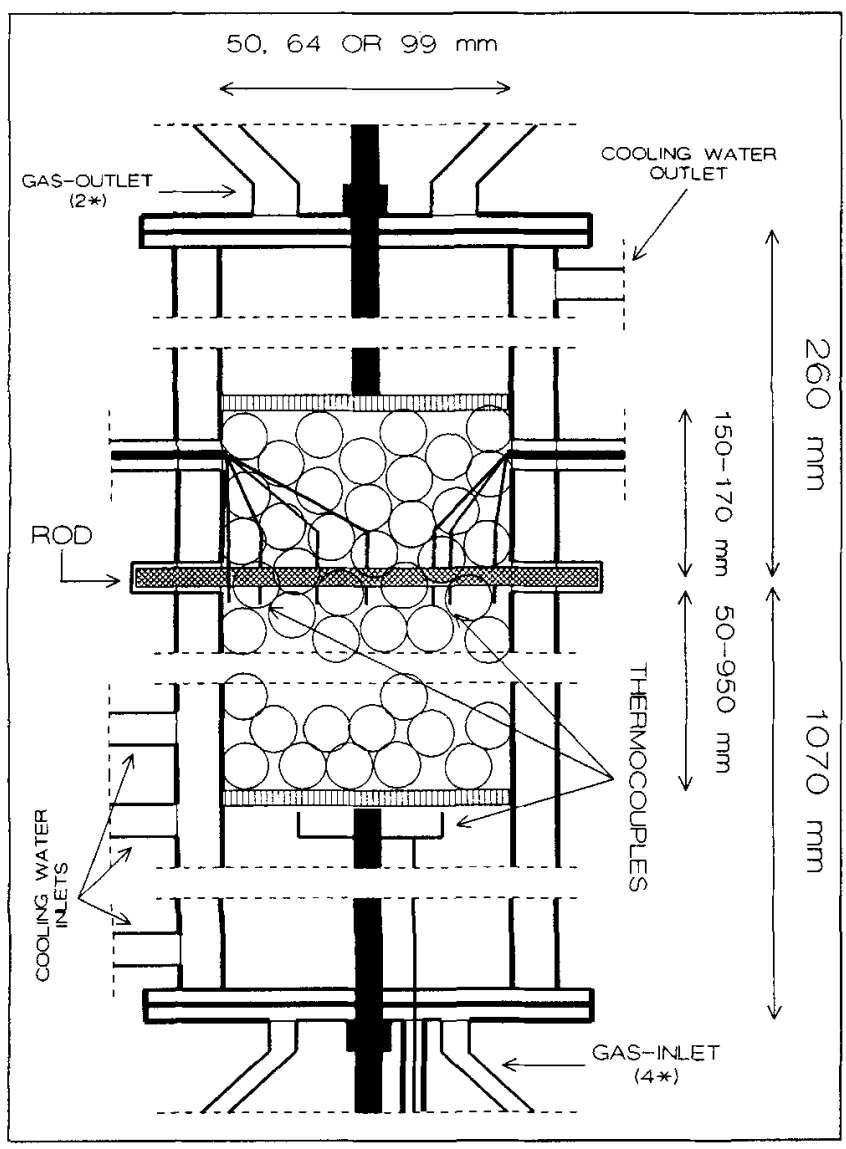

Figure 2. Wall cooled tubes.

bed. The rod consisted of a low conducting material, so that the measured temperatures were not influenced by conduction through this rod. The temperature of the gas at the inlet of the packed bed, the coolant temperature at the inlet and outlet, the pressure before and after the bed, and the gas flow rate were also measured. The pressure drop over the packed bed was always lower than 0.1 bar and therefore neglected. Figure 1 shows the setup, and Figure 2 the tubes.

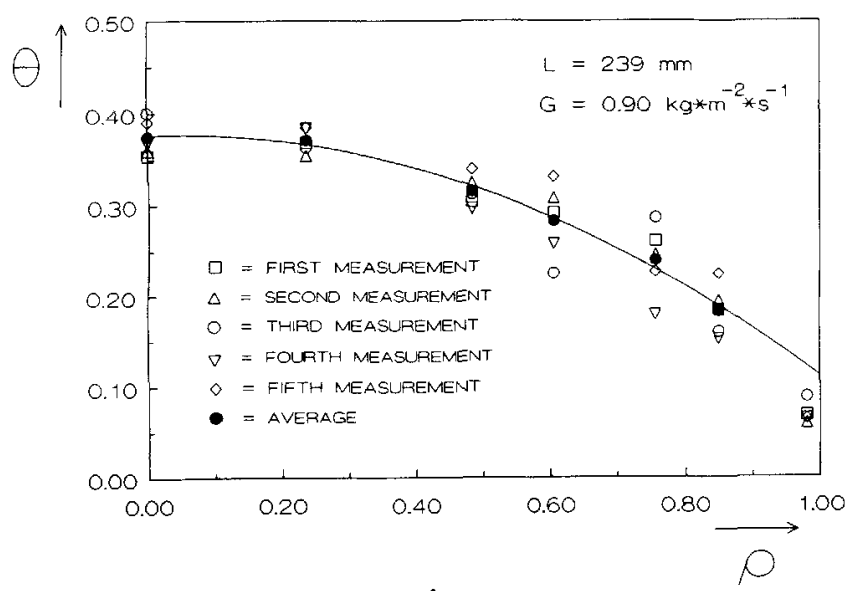

A
The bed height in the tubes could be increased by lowering the piston in the bottom of the tubes and adding extra packing material, keeping the top of the packing at the same place in the tube. By changing the bed height in this way it was possible to obtain radial temperature profiles at different axial positions or bed lengths. The tubes were also designed in such a way that the bed could easily be repacked by fluidizing the packing for a short time. Care was taken to keep the bed height, and thus the average bed porosity, always the same for one experimental series. In Figure 3, two examples of measured radial temperature profiles are given. Individual dimensionless radial temperature profiles, as obtained from the measurements, were averaged to one mean profile for a certain bed length. By doing so, also values for the standard deviation for every radial point were obtained. Combination of the average radial temperature profiles, obtained for different bed heights at the same experimental conditions, gave a temperature field for the whole tube.

All experiments reported here have been performed with air at atmospheric pressure, for which the following physical properties at 1 bar and $313 \mathrm{~K}$ were used: $\rho_{g}=1.13 \mathrm{~kg} \cdot \mathrm{m}^{-3}$; $C p_{g}=1,014 \quad \mathrm{~J} \cdot \mathrm{kg}^{-1} \cdot \mathrm{K}^{-1} ; \quad \eta_{g}=19.04 \times 10^{-6} \quad \mathrm{~Pa} \cdot \mathrm{s}$; and $\lambda_{g}=27.2 \times 10^{-3} \mathrm{~W} \cdot \mathrm{m}^{-1} \cdot \mathrm{K}^{-1}$. For the experiments, the following packings were used: glass spheres with $d_{p}^{e}=3.7 \mathrm{~mm}$ and $d_{p}^{e}=7.2 \mathrm{~mm}$; porous alumina full cylinders with $d_{p}^{e}=5.9 \mathrm{~mm}$ $(d \times h=6.4 \times 5.2 \mathrm{~mm})$; and porous alumina Raschig rings, as used for the oxidation of ethylene, with $d_{p}^{e}=6.2 \mathrm{~mm}$ $\left(d_{u} \times d_{i} \times h=8.5 \times 3.1 \times 8.6 \mathrm{~mm}\right)$. Measured average bed porosities are given in Table 1 for different tubes and packings used. Temperatures, measured very close to the tube wall, were probably influenced by the coolant temperature. Therefore, these temperatures were never used for obtaining values for the heat-transport coefficients. For a more detailed description of the experimental setup, the packings used and the measuring procedure, see Borkink (1991).

\section{Experimental Results}

\section{Two-dimensional model}

For the pseudo-homogeneous two-dimensional model, two effective heat-transport coefficients were obtained: the effec-

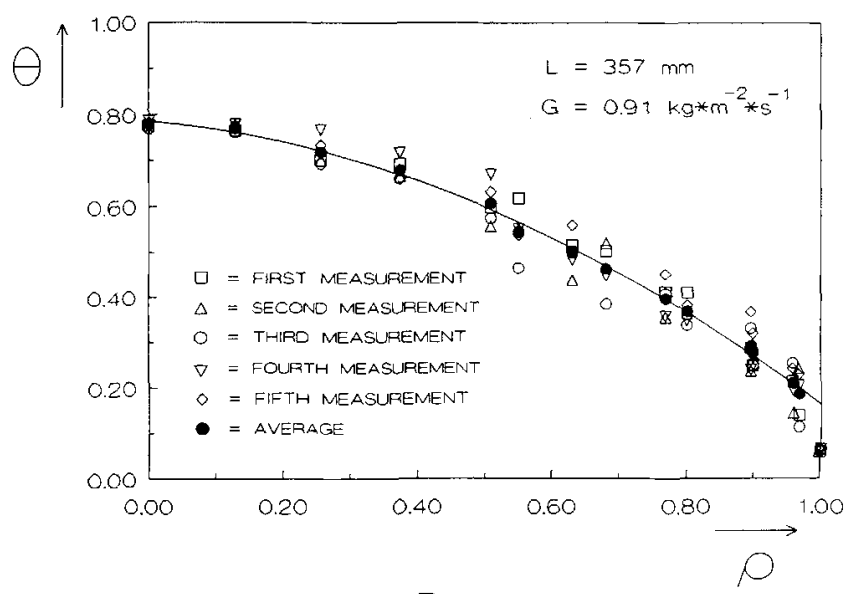

B

Figure 3. Experimentally determined radial temperatures and fitted parabolic profile for alumina cylinders with $d_{p}^{\ominus}$ $=5.9 \mathrm{~mm}$ : A. tube I with $D_{t}=49.9 \mathrm{~mm}$; B. tube III with $D_{t}=99.0 \mathrm{~mm}$. 
Table 1. Measured Average Bed Porosities of Tubes and Packings for the Experiments

\begin{tabular}{lccc}
\hline & $\begin{array}{c}\text { Tube I } \\
D_{t}=49.9 \mathrm{~mm}\end{array}$ & $\begin{array}{c}\text { Tube II } \\
D_{t}=63.5 \mathrm{~mm}\end{array}$ & $\begin{array}{c}\text { Tube III } \\
D_{t}=99.0 \mathrm{~mm}\end{array}$ \\
\hline $\begin{array}{l}\text { Packing A Glass Spheres } \\
d_{p}^{e}=3.7 \mathrm{~mm}\end{array}$ & $\mathrm{X}$ & $\mathrm{X}$ \\
$\frac{\text { Packing B Glass Spheres }}{d_{p}^{e}=7.2 \mathrm{~mm}}$ & 0.36 & 0.38 & 0.37 \\
$\frac{\text { Packing C Cylinders }}{d_{p}^{e}=5.9 \mathrm{~mm}}$ & 0.39 & 0.36 & 0.35 \\
$\frac{\text { Packing D Raschig Rings }}{d_{p}^{e}=6.2 \mathrm{~mm}}$ & 0.39 & $\mathrm{X}$ & 0.47 \\
\hline
\end{tabular}

tive radial heat conductivity $\lambda_{e, r}$ and the wall heat-transfer coefficient $\alpha_{w}$. Values for these coefficients were obtained for different gas flow rates, tube diameters, and packings, using Eqs. 3, 4 and 9.

In Figures $4 a-4 c$, best-fit values for $\lambda_{e, r}$ are given as a function of the gas flow rate for three different packings. Although the type of gas was not changed, a molecular Peclet number $P e_{p}$ is used for making the gas flow rate dimensionless, in accordance with the results of Agnew and Potter (1970) and Olbrich and Potter (1972), for example. In these figures, the parameter $\lambda_{r}^{*}$ is correlated by:

$$
\lambda_{r}^{*}=\lambda_{o}^{*}+\frac{\epsilon_{b} P e_{p}^{i}}{B o_{h, r}^{\infty}}
$$

in which $\lambda_{r}^{*}=\lambda_{e, r} / \lambda_{g}$. The best-fit values for the parameters $\lambda_{0}^{*}$ and $B o_{h, r}^{\infty}$ are given in the figures for different tubes and packings used. Note, that all the effective conductivities in this article are based on the total surface area in radial direction and that the Bodenstein numbers are based on the superficial velocity. The effective radial heat conductivity can be correlated as a linear function of the gas flow rate for all the experiments performed. This supports the theory that the effective radial heat conductivity consists of a flow-dependent and a flow-independent term. In literature, the flow-dependent term is often assumed to be a function of the number of particles on a diameter $N$. This dependence is thought to be the results of the existence of a radial velocity profile (Fahien and Smith, 1955; Tsotsas and Schlünder, 1988) or of the reflection of the gas at the tube wall (Schlünder, 1966). Fahien and Smith (1955) correlated the dependence of the number of particles on a diameter for their mass-transport experiments as:

$$
B o_{m, r}^{\infty}=C\left(1+\frac{19.4}{N^{2}}\right)
$$

in which $C$ lies between 8-12. Schlünder (1966) derived the following equation for the Bodenstein-mass number at fully developed turbulent flow:

$$
B o_{m, r}^{\infty}=8\left[2-\left(1-\frac{2}{N}\right)^{2}\right]
$$

Although these results were obtained for mass transport, it is generally believed that these values can also be used for radial heat transport. Both Eqs. 11 and 12 predict a decrease of the $B o_{h, r}^{\infty}$ number with an increasing number of particles on a diameter. Figure $4 \mathrm{a}$ shows that this is indeed so for the tube with $D_{t}=49.9 \mathrm{~mm}$, filled with glass spheres of $d_{p}^{e}=7.2 \mathrm{~mm}$ $(N=6.9)$ and $d_{p}^{e}=3.7 \mathrm{~mm}(n=13.5)$, respectively. But, if the tube-to-particle diameter ratio is changed by changing the tube diameter and keeping the particle diameter the same, a decreasing value of $B o_{h, r}^{\infty}$ with increasing $N$ is not found, as can be seen from Figures $4 a-4 c$. These figures also show that the values for $\lambda_{0}$, being the intercept for $P e_{p}^{\prime}=0$, scatter much for different tube diameters. However, literature relations for $\lambda_{0}$ (for example, Zehner and Schlünder, 1970) do not predict a strong dependence of this coefficient on the tube diameter. To eliminate the effect of the scatter of the intercept on the values for the $B o_{h, r}^{\infty}$ number, $\lambda_{0}$ was fixed at the value, if a straight line is fitted to all the data simultaneously, for one packing and different tube diameters. With these values for $\lambda_{0}$, also given in Eqs. 13a-13d, values for the $B o_{h, r}^{\infty}$ number for different tubes were calculated again. These values are given in Figure 5. The Bodenstein number at turbulent flow is more or less independent of the tube diameter for the same packing and differs only for different packing shapes. Thus, it must be possible to correlate all $\lambda_{e, r}$ values for a certain packing independent of the tube diameter, as was also found experimentally by Seidel (1965). By doing so, the following correlations are obtained with our data. For glass spheres with $d_{p}^{e}=3.7 \mathrm{~mm}$, we find $B o_{h, r}^{\infty}=8.8$ :

$$
\lambda_{r}^{*}=4.7+\frac{P e_{p}^{s}}{8.8} \text { for } N=13.5 \text { and } 60<P e_{p}^{s}<300
$$

For glass spheres with $d_{p}^{e}=7.2 \mathrm{~mm}$, we find $B o_{h, r}^{\infty}=10.9$ :

$$
\lambda_{r}^{*}=6.2+\frac{P e_{p}^{s}}{10.9} \text { for } 7<N<14 \text { and } 100<P e_{p}^{s}<800
$$

For alumina cylinders with $d_{p}^{e}=5.9 \mathrm{~mm}$, we find $B o_{h, r}^{\infty}=7.6$ :

$$
\lambda_{r}^{*}=4.0+\frac{P e_{p}^{s}}{7.6} \text { for } 8<N<17 \text { and } 50<P e_{p}^{s}<450
$$

And for alumina Raschig rings with $d_{p}^{e}=6.2 \mathrm{~mm}$, we find $B o_{h, r}^{\infty}=4.2$ :

$$
\lambda_{r}^{*}=4.5+\frac{P e_{p}^{s}}{4.2} \text { for } 8 \leq N \leq 16 \text { and } 100<P e_{p}^{s}<450
$$

Note that we have correlated $\lambda_{e, r}$ as a function of the molecular 


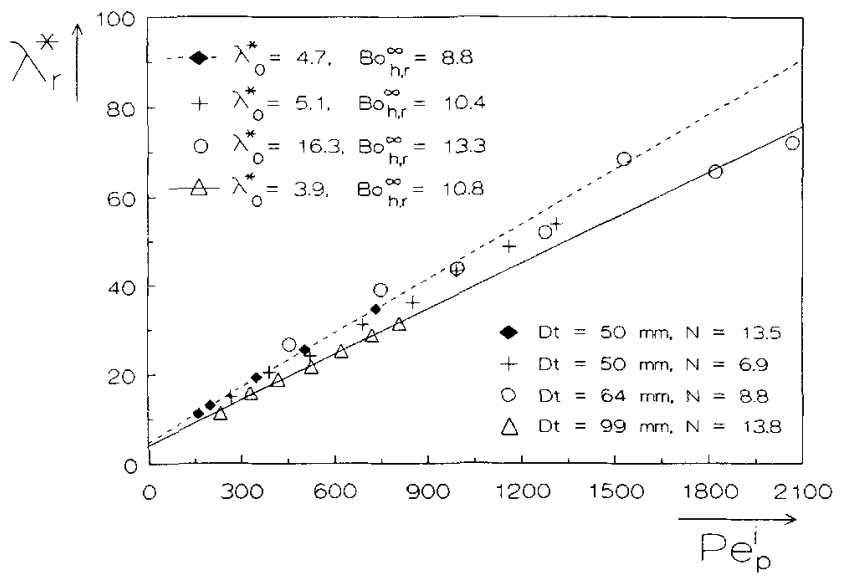

A

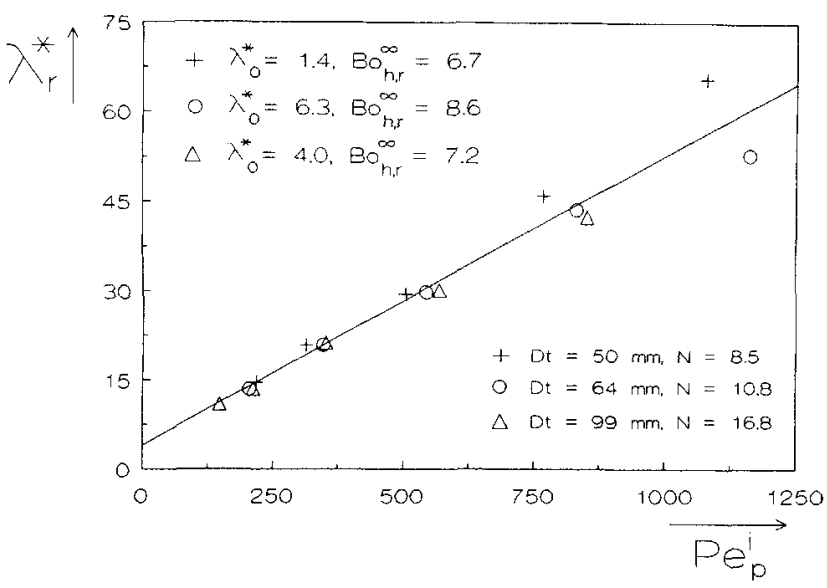

B

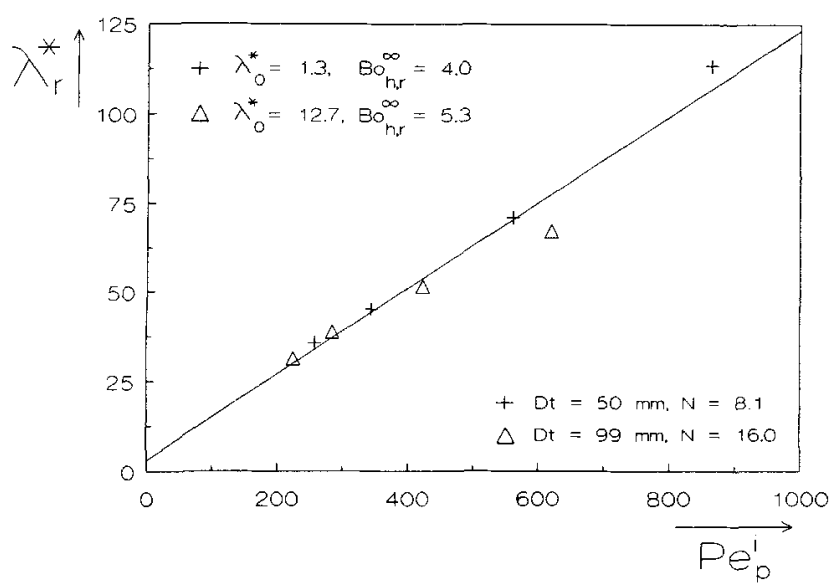

C

Figure 4. Best.fit values for $\lambda_{e, r}$ as a function of the gas flow rate for different packings: $A$. glass spheres with $d_{p}^{e}=3.7$ or $7.2 \mathrm{~mm}$; B. alumina cylinders with $d_{p}^{e}=5.9 \mathrm{~mm}$; C. alumina Raschig rings with $d_{p}^{e}=6.2 \mathrm{~mm}$.

Peclet number based on the superficial velocity $P e_{p}^{s}$ instead of the interstitial velocity $P e_{p}^{i}$, as used in Figures $4 a-4 c$. The values for the $B o_{h, r}^{\infty}$ number are close to those by Gunn (1987), being

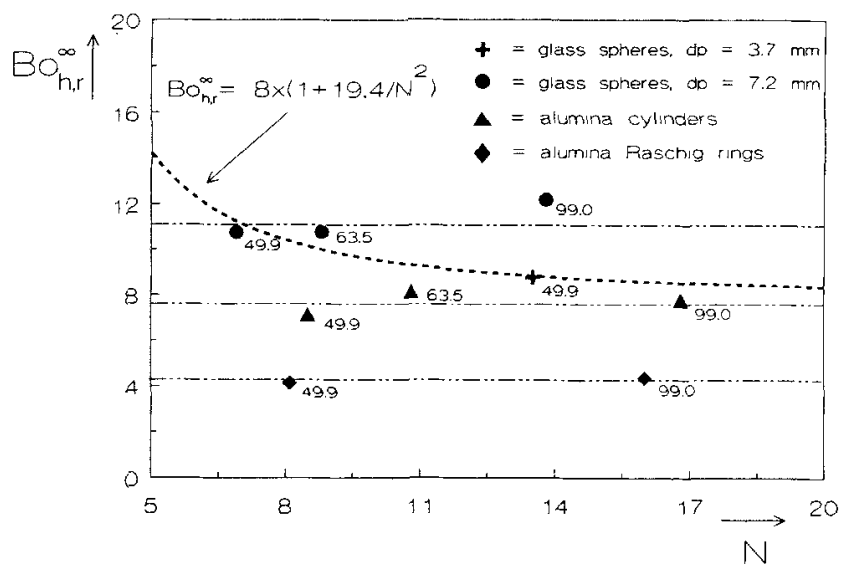

Figure 5. Experimental values for the radial Bodensteinheat number at fully developed turbulent flow as a function of the number of particles on a diameter. The tube diameters in $\mathrm{mm}$ are given at the symbols in the figure.

11 for spheres, 8 for full cylinders, and 5.7 for hollow cylinders, and those by Dixon (1988) being 12,7 , and 6 , respectively.

Best-fit values for the wall heat-transfer coefficient are given in Figures $6 \mathrm{a}-6 \mathrm{c}$. In these figures the parameter $\alpha_{w}^{*}$ is correlated by:

$$
\alpha_{w}^{*}=A_{0}+a P e_{p}^{i}
$$

in which $\alpha_{w}^{*}=\alpha_{w} d_{p}^{e} / \lambda_{g}$. In literature, the wall heat-transfer coefficient $\alpha_{w}$ for a packed bed and the gas flow rate is correlated often as a power function, in analogy to the heat-transfer coefficient for an empty tube (Gunn and Khalid, 1975; Li and Finlayson, 1977; Gunn et al., 1987). But, with our data a straight line can be used equally well to describe individual results per packing and per tube, as was also found by Yagi and Kunii (1960), De Wasch and Froment (1972), and Ziolkowski and Legawiec (1987). Best-fit values for parameters $A_{0}$ and $a$ are given in the figures for different tubes and packings used. Figures $6 a-6 c$ show that the wall heat-transfer coefficient is not influenced significantly by the tube diameter. If $\alpha_{w}$ is correlated per packing, the following correlations are obtained. For glass spheres with $d_{p}^{e}=3.7$ and $7.2 \mathrm{~mm}$ :

$$
\begin{aligned}
\alpha_{w}^{*}=16.30+21.7 \times 10^{-3} P e_{p}^{i} \text { for } 7 \\
<N<14 \text { and } 100<P e_{p}^{i}<2,000
\end{aligned}
$$

For full cylinders with $d_{p}^{e}=5.9 \mathrm{~mm}$ :

$$
\begin{aligned}
\alpha_{w}^{*}=10.05+21.3 \times 10^{-3} P e_{p}^{i} \text { for } 8 \\
<N<17 \text { and } 200<P e_{p}^{i}<1,250
\end{aligned}
$$

And for Raschig rings with $d_{p}^{e}=6.2 \mathrm{~mm}$ :

$$
\begin{array}{rl}
\alpha_{w}^{*}=17.94+18.4 \times 10^{-3} & P e_{p}^{i} \text { for } 8 \\
& <N<16 \text { and } 200<P e_{p}^{i}<900
\end{array}
$$




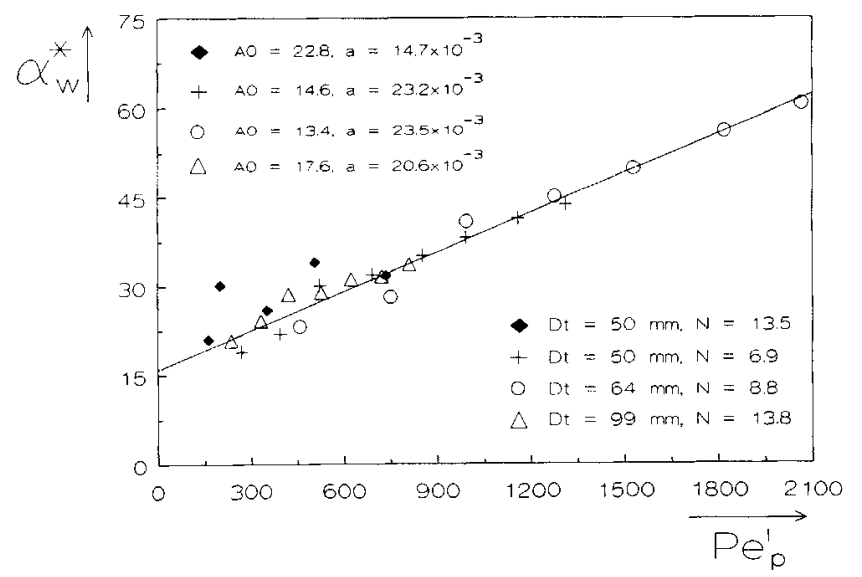

A

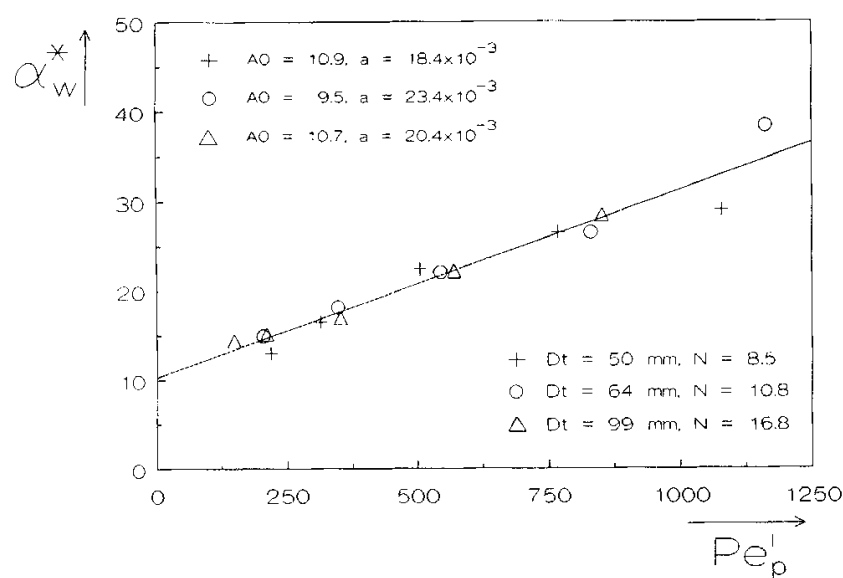

B

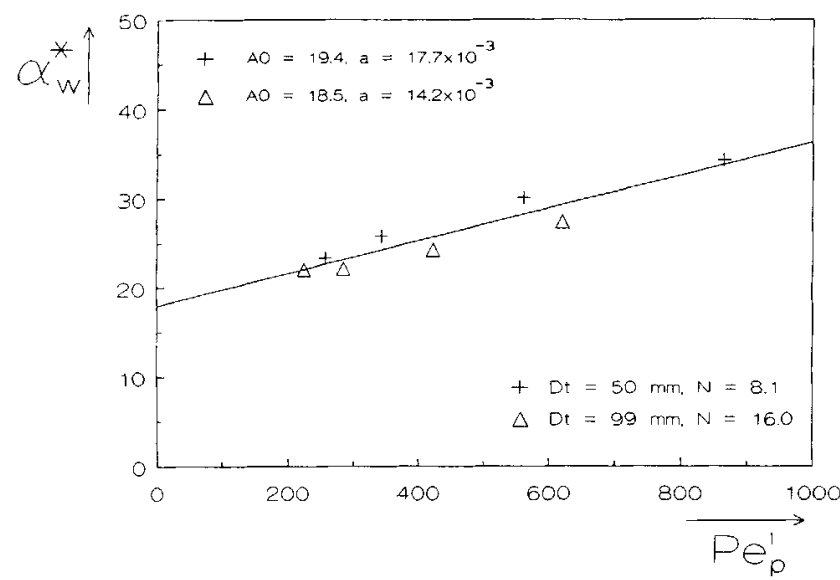

C

Figure 6. Best fit values for $\alpha_{W}$ as a function of the gas flow rate for the different packings: $A$. glass spheres with $d_{p}^{e}=3.7$ or $7.2 \mathrm{~mm}$; B. alumina cylinders with $d_{\rho}^{\circ}=5.9 \mathrm{~mm}$; C. alumina Raschig rings with $d_{p}^{e}=6.2 \mathrm{~mm}$.

\section{One-dimensional model}

For the pseudo-homogeneous one-dimensional model, only the overall heat-transfer coefficient $U_{o v}$ is obtained from the experiments for different gas flow rates, tube diameters, and

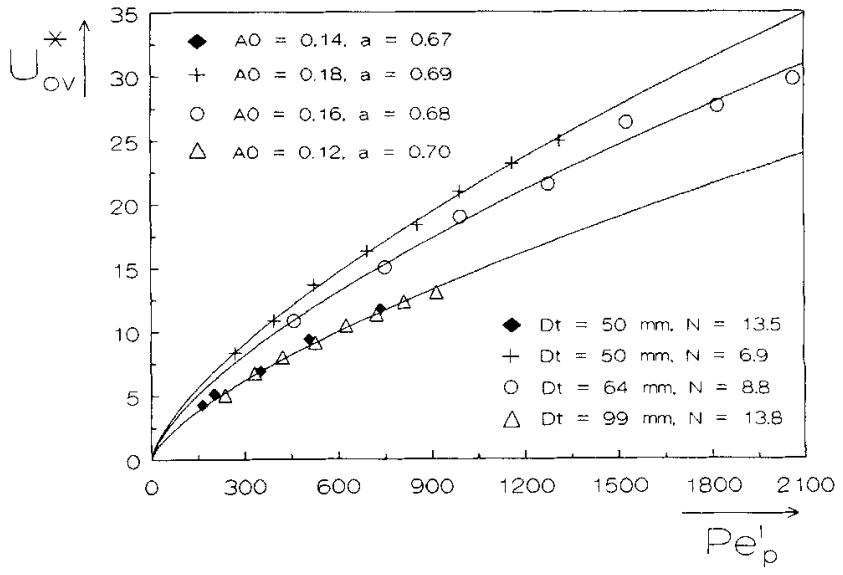

A

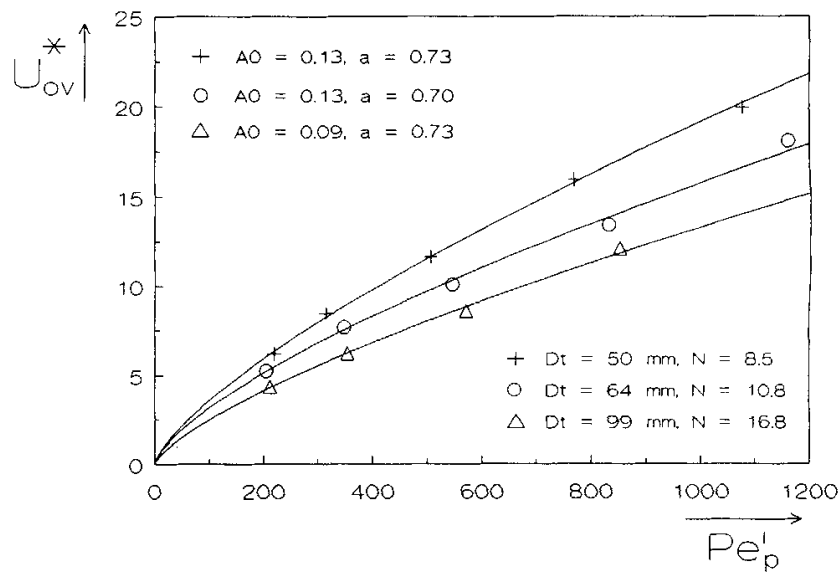

B

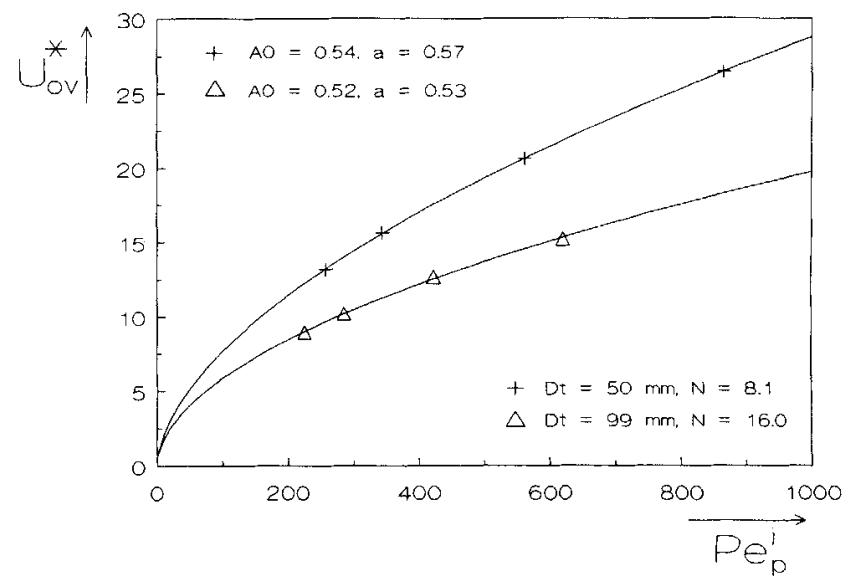

C

Figure 7. Best-fit values for $U_{o r}$ as a function of the gas flow rate for different packings: $A$. glass spheres with $d_{p}^{\circ}=3.7$ or $7.2 \mathrm{~mm}$; B. alumina cylinders with $d_{\rho}^{\theta}=5.9 \mathrm{~mm}$; C. alumina Raschig rings with $d_{p}^{\circ}=6.2 \mathrm{~mm}$.

packings, using Eqs. 7 and 9. In Figures 7a-7c, best-fit values are given as a function of the gas flow rate for the three different packings. In these figures, the parameter $U_{o v}^{*}$ is correlated by: 


$$
U_{o v}^{*}=A_{0}\left\{P e_{p}^{i}\right\}^{a}
$$

in which $U_{o v}^{*}=U_{o v} d_{p}^{e} / \lambda_{g}$. Best-fit values for parameters $A_{0}$ and $a$ are given in the figures, for different tubes and packings used.

The relation between the overall heat-transfer coefficient, and the effective radial heat conductivity, and the wall heattransfer coefficient has been studied by many authors. Beek (1962) introduced the well known "lump equation," which can be written in dimensionless form as:

$$
\frac{1}{U_{o v}^{*}}=\frac{1}{\alpha_{w}^{*}}+\frac{N}{\beta \lambda_{r}^{*}}
$$

in which $\beta$ is the so-called "lump-factor." Is is possible to obtain a best-fit value for this factor by fitting Eq. 17 to experimentally obtained values for $U_{o v}, \lambda_{e, r}$, and $\alpha_{w}$. This was done with our data using a square target function and minimized with a golden section search in one dimension (Press et al., 1989). The best-fit value for the lump factor for all our data was: $\beta=7.39$. With this value, a parity plot showed all the data to fall well within a $10 \%$ range.

It is difficult to derive a simple relation between the overall heat-transfer coefficient and the gas flow rate, particle diameter and shape, and tube diameter from Figures $7 \mathrm{a}-7 \mathrm{c}$. However, $U_{o v}$ can be correlated using Eq. 17 together with Eqs. 13 and 15 . By doing so, the values of $U_{o v}^{*}$ calculated are well within a $10 \%$ range from the values obtained directly from the experiments.

\section{Discussion and Conclusions}

Figures $4 a-4 c$ and $6 a-6 c$ show that there is no significant influence of the tube diameter on the values for the heattransport coefficients for the pseudo-homogeneous two-dimensional model. Although inconclusive, there seems to be an influence of the particle diameter, especially on the effective radial heat conductivity, Figures $4 a$ and 5. Fahien and Smith (1955) experimentally found an increase of the Bodenstein number with the radius. They assumed this to be the result of the existence of a radial porosity and therefore velocity profile, and correlated their Bodenstein numbers for the whole tube with the number of particles on a diameter only, see Eq. 11 . If the effective radial heat conductivity is indeed influenced only by the particle diameter, not by the tube diameter, the influence of the number of particles on a diameter on the effective transport coefficients, as found in literature, might not so much be due to the existence of a radial velocity profile and/or reflection of the gas on the tube wall. These influences are expected to depend on the tube-to-particle diameter ratio, not on the particle diameter only. A possible explanation might be that mixing phenomena on a pellet scale play a more important role in the process of radial heat transport than usually is assumed.

The particle-to-gas heat-transfer coefficient $\alpha_{p}$, which is a function of the particle diameter, should perhaps not be taken infinitely high when describing heat transport in packed beds, as is usually done in literature (Dixon, 1985a; Dixon and Cresswell, 1986). This might also explain the observations by Zehner and Schlünder (1973) and Dixon (1988) that the conductivity of the solid phase plays an important role even at high gas flow rates. Unfortunately, from our results, no explicit conclusions can be drawn about the influence of the particle diameter itself, and more experimental data would be needed to this end.

From the results for $\lambda_{e, r}$, Eqs. 13a-13d, it can be concluded that this coefficient is influenced strongly by the shape of the packing material used, as is reflected in the values for $B o_{h, r}^{\infty}$. Values for $\lambda_{0}^{*}$, representing the stagnant term of the effective radial heat conductivity, are almost constant for the packing materials as used by us. In literature, several extensive correlations have been reported for this parameter (Wakao and Kato, 1969; Zehner and Schlünder, 1970). Usually these correlations are very bulky, whereas the values calculated for $\lambda_{0}^{*}$ are more or less equal under practical conditions. For an industrial reactor, normally high gas flow rates are applied, say $P e_{p}^{s}>500$. In this case, the contribution of the stagnant term to the effective radial heat conductivity is small. So it is more important to have good estimates of the $B o_{h, r}^{\infty}$ number. For high gas velocities, values for $\lambda_{0}^{*}$ can safely be estimated from a simple relation, which was proposed by Krupiczka (1967) (see also Wakao and Kaguei, 1982).

From the results for $\alpha_{w}$, Eqs. 15a-15c, it can be concluded that this coefficient is influenced less by the particle shape. The values found for glass spheres and alumina Raschig rings are more or less the same. This might be explained by the fact that the Raschig ring used here is an industrially used catalyst without sharp edges. Probably, therefore, the heat transport very close to the wall of the tube is similar to that for glass spheres at low gas velocities. For the alumina cylinders it is found that the resistance to heat transport close to the wall is higher than for glass spheres and Raschig rings, especially at low gas velocities. For this, no conclusive reason was found. The alumina cylinders used here were almost perfect cylinders with sharp edges, and an ordering of this packing at the wall was observed visually. This ordering might lead to higher values of $\alpha_{w}$ because of the increased contact area of the packing with the wall and the decreased porosity near the wall. On the other hand, the decreased porosity may decrease the "wall channeling" of the gas, thereby decreasing the gas velocity at the wall and therefore the rate of heat transport.

If our results are compared to correlations in literature, relatively good agreement is found for the effective radial heat conductivity, Figure 8, but less so for the wall heat-transfer coefficient, Figure 9. Especially for $\alpha_{w}$, a large spread is found in the values presented by different authors. For this, several explanations have been put forward.

1. There were errors in the temperature measurements and in the evaluation of the experimental results. Several ways to obtain values for the heat-transport coefficients have been discussed by Li and Finlayson (1977). Especially the graphical methods, which had been often used before 1960 , can introduce large errors.

2. A radial porosity and velocity profile was present. The influence of a radial superficial velocity profile is lumped into the values for the heat-transport coefficients if their presence is not taken into account (Eigenberger and Ruppel, 1985; Borkink, 1991).

3. There were the so-called "length effect." Several authors found that the values for the heat-transport coefficients decrease with increasing bed length (Kulkarni and Doraiswamy, 1980). Thus, the values obtained are a function of the 


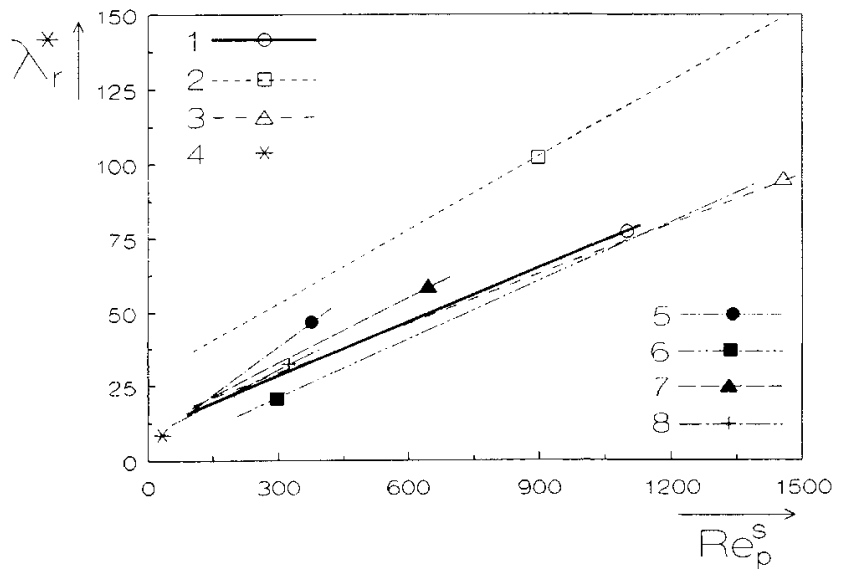

A

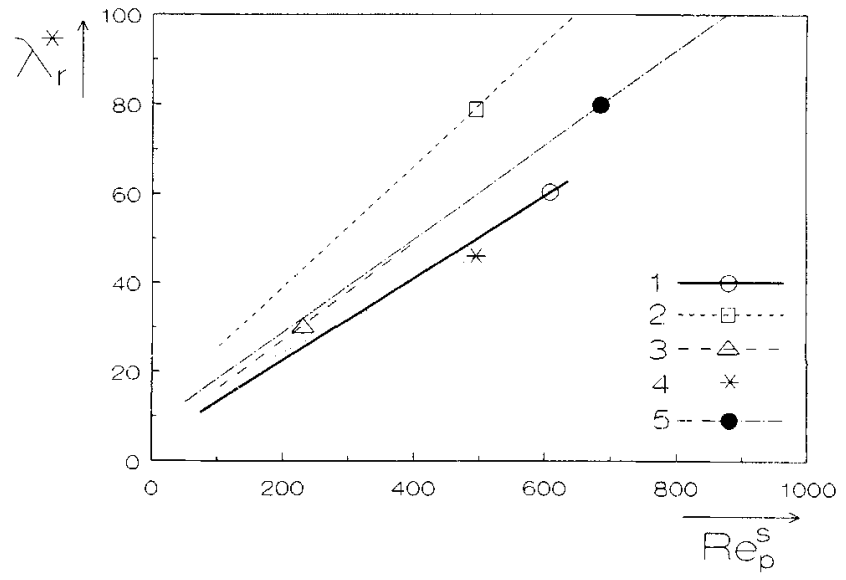

B

Figure 8. $\lambda_{\theta r}$ A. glass spheres with $d_{p}=7.2 \mathrm{~mm}$ and $N=10,1$. Eq. 13b, 2. Plautz and Johnstone (1955), 3. Calderbank and Pogorski (1957), 4. Yagi and Wakao (1959), 5. Agnew and Potter (1970), 6. Zehner and Schlunder (1973), 7. Cresswell (1986), 8. Ziolkowski and Legawiec (1987); B. alumina cylinders with $d_{p}=5.9 \mathrm{~mm}$ and $N=$ 10, 1. Eq. 13c, 2. Coberly and Marshall (1951), 3. Agnew and Potter (1970), 4. De Wasch and Froment (1972), 5. Gunn et al. (1987).

bed length and the way the experimental results are evaluated ( $\mathrm{Li}$ and Finlayson, 1977). The reasons for this length effect are: the radial velocity and temperature profiles have to develop over a certain bed length (De Wasch and Froment, 1972; Cresswell, 1986); the presence of a radial velocity profile (Hennecke and Schlünder, 1973); the radial temperature profiles are flattened by conduction through the device holding the thermocouples (Dixon, 1985b); preheating of the gas due to conduction of heat through the wall to the calming section of the bed (Dixon, 1985b); and the neglect of axial dispersion of heat (Ziolkowski and Legawiec, 1987).

We believe that much of the confusing results presented in literature can be explained by the following two phenomena.

First, the inlet temperature profile is very often assumed to be flat, whereas in reality it probably was not. Borkink et al. (1992a) showed that this introduces a length effect into the

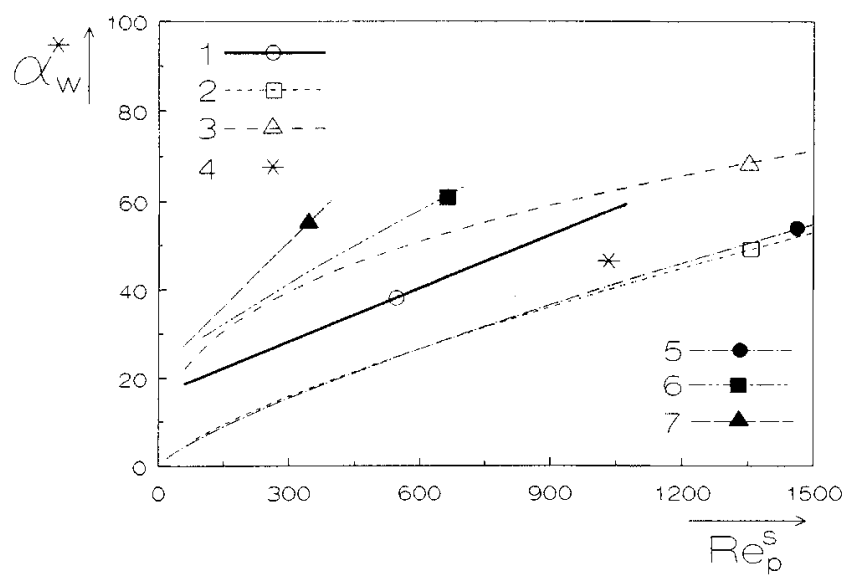

A heat-transport coefficients as obtained from cold-flow experiments. This length effect can be "compensated for" by introducing axial dispersion of heat. But, if the correct inlet temperature profile is used to evaluate the experimental results, axial dispersion can usually be neglected (Borkink and Westerterp, 1992b; Borman et al., 1992).

Secondly, the heterogeneous and discrete character of a packed bed is probably more important than usually is assumed. Especially for a low tube-to-particle diameter ratio, the assumption of the packed bed being a continuum becomes less realistic, and averaging of measured properties, like superficial velocities, porosities and temperatures, becomes more important. Only by taking the actual bed structure into account and looking at the local heat and mass-transport phenomena in packed beds, it will be possible to tell how the effective transport coefficients should be correlated as a function of the

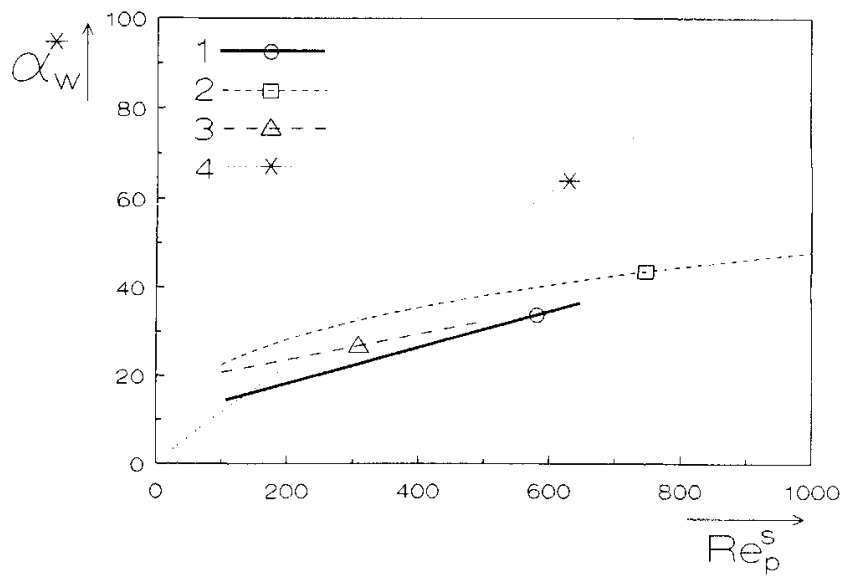

$B$

Figure 9. $\alpha_{w}$ A. glass spheres, 1. Eq. 15a, 2. Plautz and Johnstone (1955), 3. Calderbank and Pogorski (1957), 4. Yagi and Wakao (1959), 5. Li and Finlayson (1977), 6. Cresswell (1986), 7. Ziolkowski and Legawiec (1987); B. Relations for alumina cylinders, 1. Eq. 15b, 2. Coberly and Marshall (1951), 3. De Wasch and Froment (1972), 4. Li and Finlayson (1977). 
gas flow, tube and particle diameter, and so on (Mihail and Singer, 1988). Unfortunately, such models are scarcely available today, and therefore correlations for the effective heattransport coefficients still have to be used. If relations are taken from literature, we recommend to use those that are obtained for the correct inlet conditions and to use relations for $\lambda_{e, r}$ and $\alpha_{w}$ determined by the same author, because these coefficients are often cross-correlated (Wakao and Kaguei, 1982; Borkink et al., 1992a).

\section{Notation}

$A_{p}=$ external surface area of a particle, $\mathrm{m}^{2}$

$B i_{t}=\left(\alpha_{w} R_{t}\right) / \lambda_{e, r}$, tube Biot number

$B o_{h, r}=\left(\rho_{g} C p_{g} v d_{p}^{e}\right) / \lambda_{e, r}$, Bodenstein number for radial dispersion of heat

$B o_{h, r}^{\infty}=$ Bodenstein number for heat at fully developed turbulent flow

$B o_{h, r}^{\theta}=\left(\rho_{g} C p_{g} v R_{t}^{2}\right) /\left(\lambda_{e, r} L\right)=\left(B o_{h, r} N\right) / 4 \Gamma$, modified radial Bodenstein number for heat

$B o_{m, r}=v d_{p}^{e} / D_{e, r}$, Bodenstein number for radial dispersion of mass

$B o_{m, r}^{\infty}=$ Bodenstein number for mass at fully developed turbulent flow

$C p_{g}=$ specific heat of the gas at constant pressure, $\mathrm{J} \cdot \mathrm{kg}^{-1} \cdot \mathrm{K}^{-1}$

$D_{e, r}=$ effective radial mass dispersion coefficient, $\mathrm{m}^{2} \cdot \mathrm{s}^{-1}$

$D_{1}=$ tube diameter, $\mathrm{m}$

$d_{p}^{e}=\left(6 V_{p}\right) / A_{p}$, equivalent diameter of a sphere, $\mathrm{m}$

$G=\rho_{g} v$, superficial gas mass flow rate, $\mathrm{kg} \cdot \mathrm{m}^{-2} \cdot \mathrm{s}^{-1}$

$J_{0}, J_{1}=$ zeroth- and first-order Bessel functions of the first kind (Abramowitz and Stegun, 1972)

$L=$ bed length, $\mathrm{m}$

$N=D_{t} / d_{p}^{e}$, number of particles on a diameter

$P e_{p}^{i}=\left(\rho_{g} C p_{g} u d_{p}^{e}\right) / \lambda_{g}=R e_{p}^{i} P r$, molecular Peclet number based on the interstitial velocity

$P e_{p}^{s}=\left(\rho_{g} C p_{g} v d_{p}^{e}\right) / \lambda_{g}$, molecular Peclet number based on the superficial velocity

$\operatorname{Pr}=\left(\eta_{g} C p_{g}\right) / \lambda_{g}$, Prandtl number for the gas

$r=$ radial coordinate, $\mathrm{m}$

$R \boldsymbol{e}_{p}^{i}=\left(\rho_{g} u d_{p}^{e}\right) / \eta_{g}$, Reynolds number based on the interstitial velocity

$R_{t}=$ tube radius, $\mathrm{m}$

$S t=U_{o v} /\left(\rho_{g} C p_{g} v\right)$, Stanton number for the overall heat-transfer coefficient

$S t^{\theta}=\left(U_{o v} L\right) /\left(\rho_{g} C p_{g} v D_{t}\right)=S t \Gamma$, modified Stanton number

$T=$ temperature, $\mathrm{K}$

$u=v / \epsilon_{b}$, interstitial gas velocity, $\mathrm{m} \cdot \mathrm{s}^{-1}$

$U_{o v}=$ overall heat-transfer coefficient, $\mathrm{W} \cdot \mathrm{m}^{-1} \cdot \mathrm{K}^{-1}$

$U_{o v}^{*}=\left(U_{o v} d_{p}^{e}\right) / \lambda_{g}$, dimensionless overall heat-transfer coefficient

$v=$ superficial gas velocity, $\mathrm{m} \cdot \mathrm{s}^{-1}$

$V_{p}=$ volume of particle, $\mathrm{m}^{3}$

$z=$ axial coordinate, $\mathrm{m}$

\section{Greek letters}

$\alpha_{\mathrm{w}}=$ wall heat-transfer coefficient, $\mathrm{W} \cdot \mathrm{m}^{-2} \cdot \mathrm{K}^{-1}$

$\alpha_{w}^{*}=\left(\alpha_{w} d_{p}^{e}\right) / \lambda_{g}$, dimensionless wall heat-transfer coefficient

$\beta=$ lump factor, Eq. 17

$\beta_{i}=$ root of Eq. 4

$\chi^{2}=$ chi-square target function, Eq. 9

$\epsilon_{b}=$ average porosity of the bed

$\eta_{g}=$ dynamic viscosity of the gas, $\mathrm{Pa} \cdot \mathrm{s}$

$\Gamma=L / D_{t}$, tube slenderness

$\lambda_{\mathrm{g}}=$ heat conductivity of the gas, $\mathrm{W} \cdot \mathrm{m}^{-1} \cdot \mathrm{K}^{-1}$

$\lambda_{e, r}=$ effective radial heat conductivity, $\mathrm{W} \cdot \mathrm{m}^{-1} \cdot \mathrm{K}^{-1}$

$\lambda_{0}=$ effective heat conductivity of the packed bed with a stagnant fluid, $\mathrm{W} \cdot \mathrm{m}^{-1} \cdot \mathrm{K}^{-1}$

$\lambda_{r}^{*}=\lambda_{e} / \lambda_{g}$, dimensionless effective radial heat conductivity

$\lambda_{0}^{*}=\lambda_{0} / \lambda_{g}$, dimensionless effective heat conductivity of the packed bed with a stagnant fluid

$\omega=z / L$, dimensionless axial coordinate

$\rho=r / R_{t}$, dimensionless radial coordinate

$\rho_{g}=$ density of the gas, $\mathrm{kg} \cdot \mathrm{m}^{-3}$

$\sigma=$ standard deviation
$\theta=\left(T-T_{c l}\right) /\left(T_{0}-T_{c l}\right)$, dimensionless temperature

$\theta^{M C}=$ dimensionless mean-cup temperature, Eq. 8

\section{Subscripts}

$$
\begin{aligned}
c l & =\text { coolant } \\
e & =\text { effective } \\
g & =\text { gas } \\
p & =\text { particle } \\
r & =\text { radial } \\
t & =\text { tube } \\
w & =\text { wall }
\end{aligned}
$$

\section{Superscripts}

$$
\begin{aligned}
& e=\text { equivalent } \\
& i=\text { interstitial } \\
& s=\text { superficial }
\end{aligned}
$$

\section{Literature Cited}

Abramowitz, M., and I. A. Stegun, Handbook of Mathematical Functions, with Formulas, Graphs and Mathematical Tables, Wiley, New York (1972).

Agnew, J. B., and O. E. Potter, "Heat Transfer Properties of Packed Tubes of Small Diameter," Trans. Instn. Chem. Engrs., 48, T15 (1970).

Argo, W. B., and J. M. Smith, "Heat Transfer in Packed Beds: Prediction of Radial Rate in Gas-Solid Beds," Chem. Eng. Prog., 49, 443 (1953).

Baron, T., "Generalized Graphical Method for the Design of FixedBed Catalytic Reactors," Chem. Eng. Prog., 48, 118 (1952).

Bauer, R., "Effektive Radiale Wärmeleitfähigkeit Gasdurchströmter Schüttungen mit Partikeln Unterschiedlicher Form und Gröszenverteilung," VDI-Forschungsheft, 582, 3 (1977).

Beek, J., "Design of Packed Catalytic Reactors," Adv. Chem. Eng., 3, 203 (1962).

Bernard, R. A., and R. H. Wilhelm, "Turbulent Diffusion in Fixed Beds of Packed Solids," Chem. Eng. Prog., 46, 233 (1950).

Berryman, J. E., and D. M. Himmelblau, "Stochastic Modeling of Reactors for Process Analysis and Design: I. Isothermal SteadyState Well Mixed and Plug.Flow Reactors," Chem. Eng. Sci., 28, 1257 (1973).

Borkink, J. G. H., "Heat Transport in Wall-Cooled Packed Beds of Low Tube-to-Particle Diameter Ratio," Thesis, Twente Univ. of Technology, Enschede, The Netherlands (1991).

Borkink, J. G. H., P. C. Borman, and K. R. Westerterp, "Modeling of Radial Heat Transport in Packed Beds-Confidence Intervals of Estimated Parameters and Choice of Boundary Conditions," Chem. Eng. Comm., accepted (1992a).

Borkink, J. G. H., and K. R. Westerterp, "The Significance of Axial Dispersion of Heat for the Description of Heat Transport in WallCooled Packed Beds," Chem. Eng. Techn., submitted (1992b).

Borman, P. C., J. G. H. Borkink, and K. R. Westerterp, "Heat Transport in a Wall-Heated Tubular Packed-Bed Reactor at Elevated Pressures and Temperatures," Chem. Eng. Comm., accepted (1992).

Bunnell, D. G., H. B. Irvin, R. W. Olson, and J. M. Smith, "Effective Thermal Conductivities in Gas-Solid Systems,"' Ind. Eng. Chem., 41, 1977 (1949).

Calderbank, P. H., and L. A. Pogorski, "Heat Transfer in Packed Beds," Trans. Instn. Chem. Engrs., 35, 195 (1957).

Coberly, C. A., and W, R. Marshall, "Temperature Gradients in Gas Streams Flowing through Fixed Granular Beds," Chem. Eng. Prog., 47, 141 (1951).

Colburn, A. P., "Heat Transfer and Pressure Drop in Empty, Baffled and Packed Tubes: I. Heat Transfer in Packed Tubes," Ind. Eng. Chem., 23, 910 (1931).

Cresswell, D. L., "Heat Transfer in Packed Bed Reactors," Proc. NATO ASI on Chem. React. Des. Techn., Vol. 110, p. 687, H. I. de Lasa, ed., Ontario, Canada, (1986).

Crider, J. E., and A. S. Foss, "Effective Wall Heat Transfer Coefficients and Thermal Resistances in Mathematical Models of Packed Beds," AIChE J., 11(6), 1012 (1965). 
Deans, H. A. and L. Lapidus, "A Computational Model for Predicting and Correlating the Behavior of Fixed-Bed Reactors: I. Derivation of Model for Nonreactive Systems," AIChE J., 6(4), 656 (1960a).

Deans, H. A., and L. Lapidus, "A Computational Model for Predicting and Correlating the Behavior of Fixed-Bed Reactors: II. Extension to Chemically Reactive Systems," AlChE J., 6(4), 663 (1960b).

De Wasch, A. P., and G. F. Froment, "Heat Transfer in Packed Beds," Chem. Eng. Sci., 27, 567 (1972).

Dixon, A. G., "Thermal Resistance Models of Packed-Bed Effective Heat Transfer Parameters," AIChE J., 31(5), 826 (1985a).

Dixon, A. G., "The Length Effect on Packed Bed Effective Heat Transfer Parameters," Chem. Eng. J., 31, 163 (1985b).

Dixon, A. G., "Wall and Particle-Shape Effects on Heat Transfer in Packed Beds," Chem. Eng. Comm., 71, 217 (1988).

Dixon, A. G., and D. L. Cresswell, "Theoretical Prediction of Effective Heat Transfer Parameters in Packed Beds," AIChE J., 25(4), 663 (1979)

Dixon, A. G., and D. L. Cresswell, "Effective Heat Transfer Parameters for Transient Packed-Bed Models," AIChE J., 32(5), 809 (1986).

Dixon, A. G., M. A. DiCostanzo, and B. A. Soucy, "Fluid-Phase Radial Transport in Packed Beds of Low Tube-to-Particle Diameter Ratio," Int. J. Heat Mass Transf., 27, 1701 (1984).

Dixon, A. G., and L. A. Labua, "Wall-to-Fluid Coefficients for FixedBed Heat and Mass Transfer," Int. J. Heat Mass Transf., 28, 879 (1985).

Eigenberger, G., and W. Ruppel, "Probleme der Modellbildung bei Technischen Festbettreaktoren," Chem.-Ing.-Techn., 57, 181 (1985).

Fahien, R. W., and J. M. Smith, "Mass Transfer in Packed Beds," AIChE J., 1(1), 28 (1955).

Feyo de Azevedo, S., M. A. Romero-Ogawa, and A. P. Wardle, "Modeling of Tubular Fixed-Bed Catalytic Reactors: a Brief Review," Trans. IChemE., 68, 483 (1990).

Finlayson, B. A., "Packed Bed Reactor Analysis by Orthogonal Collocation," Chem. Eng. Sci, 26, 1081 (1971).

Froment, G. F., "Fixed-Bed Catalytic Reactors," Ind. Eng. Chem., 59, 18 (1967).

Froment, G. F., and K. B. Bischoff, Chemical Reactor Analysis and Design, 2nd ed., Wiley, New York (1990).

Froment, G. F., and H. P. K. Hofmann, "Design of Fixed-Bed GasSolid Catalytic Reactors," Chemical Reaction and Reactor Engineering, p. 373, J. J. Carberry and A. Varma, eds., Marcel Dekker, New York (1986).

Gatica, J. E., J. A. Romagnoli, A. F. Errazu, and J. A. Porras, "Steady- and Nonsteady-State Modeling of Tubular Fixed-Bed Reactors," Chem. Eng. Comm., 78, 73 (1989).

Gunn, D. J., "Axial and Radial Dispersion in Fixed Beds," Chem. Eng. Sci., 42, 363 (1987)

Gunn, D. J., M. M. Ahmad, and M. N. Sabri, "Radial Heat Transfer to Fixed Beds of Particles," Chem. Eng. Sci., 42, 2163 (1987).

Gunn, D. J., and M. Khalid, "Thermal Dispersion and Wall Heat Transfer in Packed Beds," Chem. Eng. Sci., 30, 261 (1975).

Hall, R. E., and J. M. Smith, "Design of Gas-Solid Catalytic Reactors," Chem. Eng. Prog., 45, 459 (1949).

Hennecke, F. W., and E. U. Schlünder, "Wärmeubergang in Beheizten oder Gekühlten Rohren mit Schüttungen aus Kugeln, Zylindern und Raschig-ringen," Chem.-Ing.-Techn., 45, 277 (1973).

Hofmann, H., "Fortschritte bei der Modellierung von Festbettreaktoren," Chem.-Ing.-Techn., 51, 257 (1979).

Jameson, G. J., "A Model for Liquid Distribution in Packed Columns and Trickle-Bed Reactors," Trans. Instn. Chem. Engrs., 44, T198 (1966).

Kado, T., and D. M. Himmelblau, "A Stochastic Analysis of a Nonisothermal Packed-Bed Reactor," AIChE J., 19(5), 975 (1973).

Khanna, R., and H. Seinfeld, "Mathematical Modeling of PackedBed Reactors: Numerical Solutions and Control Model Development," Adv. Chem. Eng., 13, 113 (1987).

Klingman, K. J., and H. H. Lee, "Alternating Flow Model for Mass and Heat Dispersion in Packed Beds," AIChE J., 33(3), 366 (1987).

Krambeck, F. J., R. Shinnar, and S. Katz, "Stochastic Models for Chemical Reactors," Ind. Eng. Chem. Fund., 6, 276 (1967).

Krupiczka, R., "Analysis of Thermal Conductivity in Granular Materials," Int. Chem. Eng., 7, 122 (1967).
Kulkarni, B. D., and L. K. Doraiswamy, "Estimation of Effective Transport Properties in Packed-Bed Reactors," Catal. Rev. Sci. Eng., 22, 431 (1980).

Kunii, D., and J. M. Smith, "Heat Transfer Characteristics of Porous Rocks," AIChE J., 6(1), 71 (1960).

Kunii, D., M. Suzuki, and N. Ono, "Heat Transfer from Wall Surface to Packed Beds at High Reynolds Number," J. Chem. Eng. Japan, 1,21 (1968).

Leva, M., "Heat Transfer to Gases through Packed Tubes: General Correlation for Smooth Spherical Particles," Ind. Eng. Chem., 39, 857 (1947)

Leva, M., and M. Grummer, "Heat Transfer to Gases through Packed Tubes: Effect of Particle Characteristics," Ind. Eng. Chem., 40, 415 (1948).

Li, C. H., and B. A. Finlayson, "Heat Transfer in Packed Beds-a Reevaluation," Chem. Eng. Sci., 32, 1055 (1977).

Melanson, M. M., and A. G. Dixon, "Solid Conduction in Low $D t / d p$ Beds of Spheres, Pellets and Rings," Int. J. Heat Mass Transf., 28, 383 (1985).

Mihail, R., and C. Singer, "Simulation of Residence Time Distributions in a Packing of Equal Spheres Using a Structural Model for a Fixed Bed," Chem. Eng. Sci., 43, 2781 (1988).

Morales, M., C. W. Spinn, and J. M. Smith, "Velocities and Effective Thermal Conductivities in Packed Beds," Ind. Eng. Chem., 43, 225 (1951).

Odendaal, W., W. Gobie, and J. J. Carberry, "Thermal Parameter Sensitivity in the Simulation of the Nonisothermal Nonadiabatic Fixed-Bed Catalytic Reactor-the Two-Dimensional Heterogeneous Model," Chem. Eng. Comm., 58, 37 (1987).

Olbrich, W. E., J. B. Agnew, and O. E. Potter, "Dispersion in Packed Beds and the Cell Model," Trans. Instn. Chem. Engrs., 44, T207 (1966).

Olbrich, W. E., and O. E. Potter, "Heat Transfer in Small-Diameter Packed Beds," Chem. Eng. Sci., 27, 1723 (1972).

Plautz, D. A., and H. F. Johnstone, "Heat and Mass Transfer in Packed Beds," AIChE J., 1(2), 193 (1955).

Porter, K. E., "Liquid Flow in Packed Columns: I. the Rivulet Model," Trans. Instn. Chem. Engrs., 46, T69 (1968).

Press, W. H., B. P. Flannery, S. A. Teukolsky, and W. T. Vetterling, Numerical Recipes in Pascal: the Art of Scientific Computing, Cambridge Univ. Press, Cambridge (1989).

Raghuraman, J., and V. Mohan, "A Markov Chain Model for Residence Time and Contact Time Distributions in Packed Beds," Chem. Eng. Sci., 30, 549 (1975)

Rhee, H. K., D. Foley, and N. R. Amundson, "Creeping Reaction Zone in a Catalytic Fixed-Bed Reactor: a Cell Model Approach," Chem. Eng. Sci., 28, 607 (1973).

Schertz, W. W., and K. B. Bischoff, "Thermal and Material Transport in Nonisothermal Packed Beds," AIChE J., 15(4), 597 (1969).

Schlünder, E. U., "Wärme- und stoffübertragung Zwischen Durchströmten Schüttungen und darin Eingebetteten Einzelkörpern," Chem.-Ing.-Techn., 38, 967 (1966).

Schlünder, E. U., and E. Tsotsas, Wärmeubertragung in Festbetten, Durchmischten Schüttgütern und Wirbelschichten., Georg Thieme Verlag, Stuttgart (1988).

Schmalzer, D. K., and H. E. Hoelscher, "A Stochastic Model of Packed-Bed Mixing and Mass Transfer," AIChE J., 17, 104 (1971).

Schnitzlein, K., and H. Hofmann, "An Alternative Model for Catalytic Fixed-Bed Reactors," Chem. Eng. Sci., 42, 2569 (1987).

Schwedock, M. J., L. C. Windes, and W. H. Ray, "Steady-State and Dynamic Modeling of a Packed-Bed Reactor for the Partial Oxidation of Methanol to Formaldehyde: II. Experimental Results Compared with Model Predictions," Chem. Eng. Comm., 78, 45 (1989).

Seidel, H. P., "Untersuchungen zum Wärmetransport in Füllkörpersäulen,"' Chem.-Ing.-Techn., 37, 1125 (1965).

Singh, P. C., G. N. Pandey, and G. Tripathi, "Models for Packed Beds," J. Scient. Ind. Res., 33, 26 (1974).

Tsotsas, E., and E. U. Schlünder, "Some Remarks on Channelling and on Radial Dispersion in Packed Beds," Chem. Eng. Sci., 43, $1200(1988)$.

Vortmeyer, D., "Packed-Bed Thermal Dispersion Models and Consistent Sets of Coefficients," Chem. Eng. Process., 26, 263 (1989).

Vortmeyer, D., and R. J. Schaefer, "Equivalence of One- and TwoPhase Models for Heat Transfer Processes in Packed Beds: One- 
Dimensional Theory," Chem. Eng. Sci., 29, 485 (1974).

Wakao, N., and S. Kaguei, Heat and Mass Transfer in Packed Beds, Gordon \& Breach, New York (1982).

Wakao, N., and K. Kato, "Effective Thermal Conductivity of Packed Beds," J. Chem. Eng. Japan, 2, 24 (1969).

Westerterp, K. R., W. P. M. van Swaaij, and A. A. C. M. Beenackers, Chemical Reactor Design and Operation, Wiley, Chichester (1984).

Wellauer, T., D. L. Cresswell, and E. J. Newson, "Heat Transfer in Packed Reactor Tubes Suitable for Selective Oxidation," ACS Symp. Ser., 169, 527 (1982).

Westerink, E. J., N. Koster, and K. R. Westerterp, "The Choice between Cooled Tubular Reactor Models: Analysis on the Hot Spot," Chem. Eng. Sci., 45, 3443 (1990).

Windes, L. C., M. J. Schwedock, and W. H. Ray, "Steady-State and Dynamic Modeling of a Packed-Bed Reactor for the Partial Oxidation of Methanol to Formaldehyde: I. Model Development," Chem. Eng. Comm., 78, 1 (1989a).

Windes, L. C., A. Cinar, and W. H. Ray, "Dynamic Estimation of Temperature and Concentration Profiles in a Packed-Bed Reactor," Chem. Eng. Sci., 44, 2087 (1989b).
Yagi, S., and D. Kunii, "Studies on Effective Thermal Conductivities in Packed Beds," AIChE J., 3, 373 (1957).

Yagi, S., and D. Kunii, "Studies on Heat Transfer Near Wall Surface in Packed Beds," AIChE J., 6, 97 (1960).

Yagi, S., and N. Wakao, "Heat and Mass Transfer from Wall to Fluid in Packed Beds," AIChE J., 5, 79 (1959).

Zehner, P., and E. U. Schlünder, "Die Effektive Wärmeleitfähigkeit von Schüttungen bei Mäszigen Temperaturen,"'Chem.-Ing.-Techn., 42, 933 (1970)

Zehner, P., and E. U. Schlünder, "Wärmeleitfähigkeit Durchströmter Kugelschüttungen bei Mäszigen und Hohen Temperaturen," Chem.Ing.-Techn., 45, 272 (1973).

Ziolkowski, D., and B. Legawiec, "Remarks upon Thermokinetic Parameters of the One- and Two-Dimensional Mathematical Models of Heat Transfer in a Tubular Flow Apparatus with a Packed Bed," Chem. Eng. Process., 21, 65 (1987).

Manuscript received Sept. 23, 1991, and revision received Mar. 11, 1992. 